\title{
Management Ability, Innovation Input and Enterprise Performance
}

\author{
Zhang Yan ${ }^{1}$ \\ ${ }^{1}$ School of Economics and Management, Beijing Jiaotong University, BJTU Beijing, China
}

\begin{abstract}
This paper studies the endogenous relationship between innovation investment and enterprise performance through the three-stage least square method, taking the companies listed on the Main board of A-shares in Shanghai and Shenzhen stock Exchanges from 2014 to 2018 as research samples, and explores whether the improvement of management ability can effectively promote the transformation of enterprise innovation investment into enterprise performance from the perspective of innovation. The research results show that there is a two-way influence between innovation input and enterprise performance. The innovation input can significantly promote the growth of enterprise performance, but its promotion effect is relatively lagged. The growth of performance may weaken the enterprise's innovation motivation and reduce the future innovation input. Management competence has a significant positive moderating effect on the relationship between innovation input and performance. This paper provides an important reference for balancing innovation and enterprise performance and improving the transformation efficiency of enterprise innovation investment to increase enterprise value.
\end{abstract}

\section{INTRODUCTION}

For enterprises, innovation is an important source of core competitiveness, and innovation is inseparable from $\mathrm{R} \&$ $\mathrm{D}$ investment in products and technology, but whether a large amount of innovation investment can be effectively and smoothly transformed into enterprise performance to enhance the value of enterprises, it is an issue of great concern to both theorists and practitioners.

There is controversy on the relationship between innovation investment and corporate performance in the existing literature. Some studies believe that R\&D investment can significantly promote the current corporate performance [1], and some studies believe that the return of R \& D investment lags behind [2]. Some studies pointed out that the relationship between innovation investment and corporate performance is non-linear [3], did not form a consistent conclusion. Only a few literatures have discussed not only the impact of innovation investment on enterprise performance, but also the reverse impact of enterprise performance on innovation investment[4-5].

As management plays a leading role in innovation activities, in recent years, research on management and innovation has emerged one after another, but most of the existing studies have focused on the background characteristics of senior executives or incentives for senior executives [6-7]. Few articles discuss the relationship between management's own ability and innovation, and do not discuss the influence of management ability on the enterprise performance of innovation, and whether the improvement of management ability can effectively promote the transformation of enterprise innovation investment into enterprise performance. Further research is needed.

The research contributions of this paper mainly include: first, this paper proves that there is indeed an endogenous causal relationship between innovation investment and corporate performance, which increases the empirical evidence of their two-way impact. Second, this paper integrates the three variables of management capabilities, innovation input and enterprise performance, and examines the regulatory role of management capabilities in the process of transforming innovation input into enterprise performance, which not only expands the research perspective of management capabilities, but also further enriches the relevant research on the economic consequences of management capabilities.

\section{THEORETICAL ANALYSIS AND RESEARCH HYPOTHESIS}

\subsection{Innovation Investment and Enterprise performance}

For enterprises, increasing investment in innovation is an important investment decision, which can affect the value of enterprises. Investing a large amount of manpower and resources in technological innovation can occupy the monopoly advantage within a certain period of time, obtain excess profits, and open up new markets; the use of 
new production technology can reduce the production cost of unit products and occupy a competitive advantage; innovative business models, or organizational management models, subvert industry order, optimize internal processes, can stimulate employees' enthusiasm for work and obtain more industry profits. Therefore, on the whole, the increase of innovation investment is to a large extent to create value, which is conducive to enhance the core competitiveness of enterprises and improve enterprise performance. However, considering that innovation investment has the characteristics of high risk, long period, accumulation and knowledge spillover, it may not significantly promote the current performance, but the cumulative effect of innovation investment will significantly improve enterprise performance. Therefore, the promotion effect of enterprise innovation investment on enterprise performance will lag behind. Based on this, this paper puts forward the research hypothesis $\mathrm{H} 1$.

H1: Enterprise innovation investment can significantly promote the growth of enterprise performance, but has a certain lag.

R\&D activity is a strategic investment activity, which has the characteristics of large upfront investment, long cycle, high risk, large capital consumption, high failure rate and so on. Innovation investment may not generate obvious income in the short term, but will increase a lot of costs and expenses. On the one hand, based on the principal-agent theory, managers who play a key role in business decision-making consider the performance of their business performance during their tenure, and when measuring short-term operating earnings and future longterm development, it is possible to make self-serving behaviors that limit innovation investment in pursuit of short-term business performance [8]. On the other hand, when corporate performance is higher than expected, enterprises may tend to be conservative and unwilling to make strategic changes to reduce innovation investment. Based on this, this paper puts forward the research hypothesis $\mathrm{H} 2$.

$\mathrm{H} 2$ : Enterprise performance will have a reverse effect on innovation investment.

\subsection{The regulating effect of management ability}

The theory of human resource management points out that the ability of management is the ability of management to make use of limited enterprise resources to create income for the enterprise. First of all, the stronger the management ability is, the more information can be observed, contacted, collected and mastered, and the stronger the ability to analyze and integrate the information obtained, which can alleviate the problem of lack of information in the process of innovation to a certain extent. Secondly, the stronger the management ability, the more it can improve the ability of resource allocation, effectively alleviate agency conflicts, improve the efficiency of resource allocation, and then improve enterprise performance. Thirdly, the stronger the management ability, the more attention is paid to improving the output of innovation and enterprise performance out of the consideration of reputation. Based on this, this paper puts forward the research hypothesis $\mathrm{H} 3$ :

H3: Management capability plays a significant positive role in regulating the relationship between innovation investment and corporate performance.

\section{RESEARCH AND DESIGN}

\subsection{Sample selection and data sources}

This paper selects the listed companies on the A-share main board of Shanghai and Shenzhen stock markets which disclosed their R\&D investment from 2014 to 2018 as research samples, and further deals with them: first, remove the samples of companies listed by ST or *ST, and then remove the samples of financial listed companies such as banks and insurance; finally, remove the samples of companies with missing relevant data. After screening, the final effective research samples are 3795. The research data used in this paper are all from CSMAR and WIND databases, and econometric analysis is carried out by using Stata13.0 statistical software. In order to avoid the influence of extreme values, the continuity variables are tailed according to $1 \%$ and $99 \%$.

\subsection{Variable definition}

Enterprise performance indicators: select the financial indicators of total asset return rate (ROA) as a measure of enterprise performance indicators.

Innovation investment index: the proportion of $R \& D$ expenditure in operating income(RD), is selected as the index to measure the innovation investment of enterprises. Management capability index: this paper uses the data Envelopment Analysis (DEA) method proposed by Demerjian et al. to measure the management ability, and uses the index (MA) to measure it.

First of all, the production efficiency of the enterprise is measured by DEA method, which is expressed by max $\theta$. Taking operating income (SALES) as the only output variable, and taking net fixed assets (PPE), R\&D expenditure, goodwill (GOODWILL), net intangible assets (INTAN), operating cost (COGS), sum of sales and management expenses (SA) as six input variables, the model (1) is established as follows:

$$
\max \theta=\frac{\text { SALES }}{\rho_{1} P P E+\rho_{2} R \& D+\rho_{3} G 00 D W L L+\rho_{4} I N T A N+\rho_{3} \operatorname{COGS}+\rho_{6} S A}
$$

Then, the Tobit model is used to calculate the management capability. Taking the obtained enterprise efficiency value as the dependent variable and the company level factor as the independent variable for truncated regression analysis, the residual term obtained is the management capability (MA). The company-level factors selected in this paper include listing life (AGE), enterprise size (SIZE), market share (MARKETSHARE), free cash flow (CASH), and controlling the year. The model (2) is as follows: 
$\theta=\mu_{0}+\mu_{1} A G E+\mu_{2} S I Z E+\mu_{3}$ MARKTESHARE + $\mu_{4} C A S H+Y E A R+\varepsilon$

Other control variables. Using the existing research for reference, the control variables are selected as follows: equity concentration degree (TOP1), equity balance degree (TOP2_10), equity nature (STATE), and independent director ratio (INDEP), and enterprise scale (SIZE), cash flow (CASH), and enterprise growth (GROWTH), asset-liability ratio (LEV).

\subsection{Model building}

Considering the interaction between innovation investment and corporate performance, this paper uses simultaneous equations for empirical test, and uses threestage least square method (3SLS) for regression estimation to improve the effectiveness of the estimation. Models (3) and (4) are constructed:

$$
\begin{aligned}
& R D_{t, t}=\alpha_{0}+\alpha_{1} R O A_{t, t}+\alpha_{2} R O A_{t, t-1}+\alpha_{3} R O A_{t, t-2}+ \\
& \theta_{l} \Sigma \text { Controls }+\sigma_{t, t} \\
& R O A_{t, t}=\beta_{0}+\beta_{1} R D_{t, t}+\beta_{2} R D_{t, t-1}+\beta_{3} R D_{t, t-2}+ \\
& \theta_{m} \Sigma \text { Controls }+\varepsilon_{t, t}
\end{aligned}
$$

In order to further study the regulatory role of management ability, the explanatory variable management ability and the interaction between innovation input and management ability are added to the basic model to build the model (5):

$$
\begin{gathered}
R O A_{t, t}=\gamma_{0}+\gamma_{1} R D_{i, t-1}+\gamma_{2} R D_{i, t-2}+\gamma_{3} M A_{i, t-1}+\gamma_{4} R D_{i, t-1} \times M A_{t, t-1} \\
+\theta_{n} \Sigma \text { Controls }+\varphi_{t, t}
\end{gathered}
$$

\section{EMPIRICAL RESULTS AND ANALYSIS}

\subsection{Descriptive statistical analysis}

Table 1 shows the descriptive statistical results of the main variables. As can be seen from Table I, the average proportion of innovation investment in the operating income of the sample company is $3.1 \%$, and the innovation investment is relatively insufficient. The average value of management ability is -0.016 , the minimum value is -0.558 , and the maximum value is 0.715 . There is a significant gap between different sample companies.

\subsection{Correlation analysis}

Table II is the correlation coefficient table between the main explanatory variables and the explained variables. It can be seen from Table 3 that there is a significant positive correlation between innovation investment and performance of sample companies at the level of $10 \%$. There is a significant positive correlation between management ability and enterprise performance and enterprise innovation investment at the level of $1 \%$. The correlation coefficients of other variables are less than 0.5 , which reflects that there is no obvious multicollinearity among the main variables, indicating that the selected variables are suitable for subsequent regression analysis.

\subsection{Endogenous test}

This paper first uses the Hausman endogenous test method to test the contemporaneity of the equation group, and the test results are shown in Table III. After the residual of all exogenous variables OLS regression in RD equation (3) is substituted into equation (4), the coefficient of regression result is -0.319 , which is significant at $1 \%$ level. The results pass the endogenous test, which shows that there is indeed an endogenous relationship between innovation investment and enterprise performance, and it is more effective to use simultaneous equations model to estimate the impact between them.

\subsection{Regression result analysis}

Considering that the economic return of innovation investment and the impact of enterprise performance on R\&D investment may lag, this paper adds the lag values of one year and two years of RD and ROA into the regression equation for intuitive comparative analysis. In Table IV, the 3SLS estimation of the impact of innovation investment on enterprise performance shows that there is a significant negative correlation between innovation investment and performance in that year, while there is a significant positive correlation between enterprise performance and innovation investment after one year and two years, which proves that innovation investment can significantly promote the growth of enterprise performance, but its promoting effect lags behind. At the same time, the 3SLS estimation of the impact of corporate performance on innovation investment shows that corporate performance has a significant negative correlation with innovation investment in the previous year, a significant positive correlation with innovation investment in the previous two years, and a negative correlation with innovation investment in that year, but not significant. It shows that the increase of enterprise performance may weaken the innovation motivation of enterprises and reduce the innovation investment in the future. At this point, hypothesis $\mathrm{H} 1$ and hypothesis $\mathrm{H} 2$ have been verified.

Next, this paper takes the enterprise performance with a lag of one year as the explained variable, and the management capability and its multiplication with the innovation investment in that year as the explanatory variable, which is substituted into the model (5) for regression. The results are shown in the last column of Table IV. The estimated results of management capability show that the interaction coefficient between management capability and innovation investment is significantly positive at the level of $1 \%$, indicating that management capability plays a significant positive role in the 
relationship between innovation investment and enterprise performance. Hypothesis $\mathrm{H} 3$ has been verified.

\subsection{Robustness test}

This paper mainly uses the method of replacing the explained variables to verify the reliability of the empirical results. Drawing lessons from the research of Feng Wenna (2010) [9], the operating profit margin
(OPM, operating profit / operating income), an indicator of corporate profitability, is used to describe corporate performance instead of ROA, and the above empirical test is repeated. The regression results show that there is no significant difference between the conclusion and the previous empirical results, indicating that the empirical results of this paper have high robustness (table outline).

TABLE I. Descriptive STATISTICAL RESUlts

\begin{tabular}{cccccc}
\hline Variables & Obs & Mean & Std & Min & Max \\
\hline ROA & 3795 & 0.038 & 0.055 & -0.158 & 0.210 \\
RD & 3795 & 0.031 & 0.032 & 0.000 & 0.21 \\
MA & 3795 & -0.016 & 0.149 & -0.558 & 0.715 \\
SIZE & 3795 & 22.870 & 1.344 & 20.287 & 26.751 \\
LEV & 3795 & 0.474 & 0.193 & 0.086 & 0.912 \\
GROWTH & 3795 & 0.106 & 0.258 & -0.459 & 1.218 \\
CASH & 3795 & 0.164 & 0.103 & 0.019 & 0.543 \\
INDEP & 3795 & 0.372 & 0.054 & 0.308 & 0.571 \\
TOP_1 & 3795 & 0.365 & 0.152 & 0.084 & 0.770 \\
TOP2_10 & 3795 & 0.206 & 0.125 & 0.023 & 0.546 \\
STATE & 3795 & 0.568 & 0.495 & 0 & 1 \\
\hline
\end{tabular}

TABLE II. CORRELATION COEFFICIENT TABLE

\begin{tabular}{|c|c|c|c|c|c|c|c|c|c|c|c|}
\hline Variable & $R O A$ & $R D$ & $M A$ & SIZE & $L E V$ & GROWTH & CASH & INDP & TOP_1 & TOP2_10 & STATE \\
\hline ROA & 1 & & & & & & & & & & \\
\hline $\mathrm{RD}$ & $0.031^{*}$ & 1 & & & & & & & & & \\
\hline MA & $0.261^{* * *}$ & $0.264^{* * *}$ & 1 & & & & & & & & \\
\hline SIZE & 0.010 & $-0.193^{* * *}$ & $0.035^{* *}$ & 1 & & & & & & & \\
\hline LEV & $-0.384^{* * *}$ & $-0.180^{* * *}$ & -0.010 & $0.491^{* * *}$ & 1 & & & & & & \\
\hline GROWTH & $0.279^{* * *}$ & $-0.035^{* *}$ & $-0.050^{* * *}$ & $0.028^{*}$ & -0.006 & 1 & & & & & \\
\hline CASH & $0.215^{* * *}$ & $0.104^{* * *}$ & $0.153^{* * *}$ & $-0.124^{* * *}$ & $-0.258^{* * *}$ & 0.006 & 1 & & & & \\
\hline INDEP & $-0.030^{*}$ & $0.035^{* *}$ & 0.024 & $0.114^{* * *}$ & $0.054^{* * *}$ & -0.002 & $0.033^{* *}$ & 1 & & & \\
\hline TOP_1 & $0.069^{* * *}$ & $-0.147^{* * *}$ & $0.099^{* * *}$ & $0.247^{* * *}$ & $0.076^{* * *}$ & $-0.083^{* * *}$ & 0.013 & $0.086^{* * *}$ & 1 & & \\
\hline TOP2_10 & $0.140^{* * *}$ & $0.046^{* * *}$ & 0.024 & $0.102^{* * *}$ & $-0.074^{* * *}$ & $0.153^{* * *}$ & $0.048^{* * *}$ & -0.001 & $-0.361^{* * *}$ & 1 & \\
\hline STATE & $-0.199^{* * *}$ & $-0.145^{* * *}$ & $0.051^{* * *}$ & $0.254^{* * *}$ & $0.227^{* * *}$ & $-0.162^{* * *}$ & $-0.030^{*}$ & $0.047^{* * *}$ & $0.266^{* * *}$ & $-0.214^{* * *}$ & 1 \\
\hline
\end{tabular}

$*, * *$ and $* * *$ mean significant at the levels of $10 \%, 5 \%$ and $1 \%$ respectively.

TABLE III. ENDOGENOUS TEST

\begin{tabular}{ccccc}
\hline Variable & Coefficient & T value & P value & ${\text { Adj. } \boldsymbol{R}^{2}}^{2}$ \\
\hline $\mathrm{e}$ & -0.319 & -5.27 & 0.000 & 0.286 \\
\hline
\end{tabular}

TABLE IV. MODEL REGRESSION RESULTS

\begin{tabular}{|c|c|c|c|}
\hline \multirow[b]{2}{*}{ Variable } & \multicolumn{2}{|c|}{ 3SLS estimation } & \multirow{2}{*}{$\begin{array}{r}\text { Regulating effect } \\
R O A\end{array}$} \\
\hline & $R D$ & $R O A$ & \\
\hline $\mathrm{RD}_{\mathrm{t}}$ & & $\begin{array}{c}-1.668^{* * *} \\
(-7.24)\end{array}$ & \\
\hline $\mathrm{RD}_{\mathrm{t}-1}$ & & $\begin{array}{c}0.957^{* * *} \\
(4.53)\end{array}$ & $\begin{array}{l}0.068 \\
(1.19)\end{array}$ \\
\hline $\mathrm{RD}_{\mathrm{t}-2}$ & & $\begin{array}{c}0.230^{* * *} \\
(3.16)\end{array}$ & $\begin{array}{l}0.129^{* *} \\
(2.06)\end{array}$ \\
\hline $\mathrm{ROA}_{\mathrm{t}}$ & $\begin{array}{l}-0.007 \\
(-0.14)\end{array}$ & & \\
\hline $\mathrm{ROA}_{\mathrm{t}-1}$ & $\begin{array}{l}-0.052^{*} \\
(-1.70)\end{array}$ & & \\
\hline $\mathrm{ROA}_{\mathrm{t}-2}$ & $\begin{array}{l}0.031^{* *} \\
(2.03)\end{array}$ & & \\
\hline MA & & & $\begin{array}{l}0.085^{* * *} \\
(12.12)\end{array}$ \\
\hline $\mathrm{RD}_{\mathrm{t}-1} * \mathrm{MA}$ & & & $\begin{array}{c}0.531^{* * *} \\
(4.41)\end{array}$ \\
\hline
\end{tabular}




\begin{tabular}{|c|c|c|c|}
\hline GROWTH & $\begin{array}{c}-0.012^{* * *} \\
(-3.71)\end{array}$ & & \\
\hline TOP1 & $\begin{array}{c}-0.026^{* * *} \\
(-6.85)\end{array}$ & & \\
\hline STATE & $\begin{array}{c}-0.003^{* * *} \\
(-2.70)\end{array}$ & & \\
\hline INDEP & $\begin{array}{c}0.042^{* * *} \\
(4.42)\end{array}$ & & \\
\hline SIZE & $\begin{array}{c}-0.004^{* * *} \\
(-8.87)\end{array}$ & $\begin{array}{l}0.007^{* * *} \\
(10.04)\end{array}$ & $\begin{array}{l}0.012^{* * *} \\
(17.03)\end{array}$ \\
\hline LEV & & $\begin{array}{l}-0.132^{* * *} \\
(-25.88)\end{array}$ & $\begin{array}{c}-0.128^{* * *} \\
(-26.64)\end{array}$ \\
\hline $\mathrm{CASH}$ & & $\begin{array}{c}0.057^{* * *} \\
(7.04)\end{array}$ & $\begin{array}{c}0.036^{* * *} \\
(4.66)\end{array}$ \\
\hline TOP2_10 & & $\begin{array}{c}0.039^{* * * *} \\
(6.00)\end{array}$ & $\begin{array}{c}0.017^{* * *} \\
(2.75)\end{array}$ \\
\hline YEAR & - & - & control \\
\hline IND & - & - & control \\
\hline _cons & $\begin{array}{c}0.113^{* * *} \\
(11.75) \\
\end{array}$ & $\begin{array}{c}-0.066^{* * *} \\
(-4.22) \\
\end{array}$ & $\begin{array}{c}-0.197^{* * *} \\
(-12.04)\end{array}$ \\
\hline $\mathrm{N}$ & 3795 & 3795 & 3795 \\
\hline$R^{2}$ & 0.044 & 0.033 & 0.358 \\
\hline
\end{tabular}

$*$,** and $* * *$ mean significant at the levels of $10 \%, 5 \%$ and $1 \%$ respectively.

\section{RESEARCH CONCLUSION}

This paper empirically tests the relationship between innovation investment and corporate performance. Then it further explores the regulatory role of management ability in it, and draw the following conclusions: (1) the innovation investment of enterprises can significantly promote the growth of enterprise performance, but its promoting role lags behind. (2) The increase of enterprise performance may weaken the innovation power of the enterprise and reduce the innovation investment in the future. (3) Management ability can significantly improve enterprise performance and play a significant positive role in the relationship between innovation investment and enterprise performance. This means that in innovation activities, the more capable the manager is, the more effectively and smoothly the innovation investment can be transformed into corporate performance, resulting in better economic returns. Therefore, it is very important to improve management ability.

\section{REFERENCES}

1. B.W. Lin,Y. Lee, and S.C. Hung. R\&D intensity and commercialization orientation effects on financial performance.Journal of Business Research, 2006, 59(6):pp.679-685.

2. L.X. Liang, Y. Jin, and N. Zhao. Research on the relationship between renewd input and corporate performance based on corporate life cycle-- from empirical data of listed companies. Science of
Science and Management of Science and Technology, 2010,31 (12): pp.11-17

3. J.L. Chen, L.J. Meng, and Q. Wang. The nonlinear relationship between R\&D investment and corporate performance of listed companies . China Science and Technology Forum, 2015 (05):pp. 67-73.

4. G. Markarian, L. Pozza, and A. Prencipe. Capitalization of R\&D costs and earnings management: evidence from Italian listed companies. International Journal of Accounting, 2008, 43(3):pp.246-267.

5. M.Q. Yin,L. Sheng, and W.B. Li. Executive incentive, innovation investment and corporate performance-an empirical study of different industries from an endogenous perspective. Nankai Management Review, 2018,21 (01):pp. 109-117

6. X.F. Quan,W.H. Cu, and H.Y. Yin. Senior executives' military experience, management style and corporate innovation. Nankai Management Review, 2019, 22 (06):pp. 140-151.

7. D.S. Zhu and X.Y. Zhou. Equity checks and balances, executive shareholding and enterprise innovation efficiency. Nankai Management Review, 2016, 19 (03):pp. 136-144.

8. W.R. Baber and F.J. Haggard. The effect of concern about reported income on discretionary spending decisions: The case of research and development. The Accounting Review, 1991, 66(4):pp.818-829.

9. W.N. Feng. Research on the relationship between R\&D input and innovation output of High-tech enterprises-- based on the empirical study of Hightech Enterprises in Shandong Province. Economic issues, 2010 (09): pp.74-78. 